\title{
Are We Aiming for Cure or Lifelong Treatment of Hypertension? All Doctors Need To Be Aware of Primary Aldosteronism. A Nationwide Study With Up To 8-Year Follow-Up
}

Hrafnhildur Gunnarsdóttir ( $\sim$ hrafnhildurg3@gmail.com )

Landspitali University Hospital https://orcid.org/0000-0003-3735-4884

\section{Gudbjorg Jonsdottir}

University of Iceland: Haskoli Islands

\section{Gudjon Birgisson}

National University Hospital of Iceland: Landspitali

Jon Gudmundsson

National University Hospital of Iceland: Landspitali

Helga Agusta Sigurjonsdottir

National University Hospital of Iceland: Landspitali

\section{Research Article}

Keywords: primary aldosteronism, saline infusion test, adrenal venous sampling, potassium supplementation, adrenalectomy

Posted Date: October 21st, 2021

DOl: https://doi.org/10.21203/rs.3.rs-980358/v1

License: (c) (1) This work is licensed under a Creative Commons Attribution 4.0 International License.

Read Full License 


\section{Abstract \\ Purpose}

Long term follow-up studies on primary aldosteronism (PA) diagnosis, treatment response and comparison of the two major subgroups - unilateral (UD) and bilateral disease (BD) - are lacking. While adrenalectomy for UD is considered effective, less is known about long-term effects of specialized treatment for BD. We present the results from our nationwide observational study, executed at Landspitali University Hospital, tertiary referral center. We aim to review results of diagnostic procedures and histopathology for PA patients diagnosed in 2012-2016 in Iceland, compare UD and BD and assess treatment response.

\section{Methods}

A total of 32 PA patients aged 28-88 years were diagnosed and treated according to current guidelines. Adrenalectomy was used for AVS-confirmed UD and mineralocorticoid receptor antagonists for BD.

\section{Results}

The majority of patients had BD, roughly half of them had a unilateral nodule. With specialized treatment, a reduction was seen in UD and BD in systolic blood pressure (BP) ( $<<0,001$, both groups), antihypertensive drug count $(p=0,002$ and $p=0,04$, respectively) and need for potassium supplementation $(p<0,001$, both groups). Diastolic BP decreased significantly in UD $(p<0,001)$.

\section{Conclusion}

Our results show similarly good treatment response in both subgroups. Ratio of hypokalemia and number of cases indicates severe PA underdiagnosis in Iceland. Adrenal nodules diagnosed using CT can be misleading and AVS is mandatory in diagnosing unilateral vs bilateral PA.

\section{Introduction}

Primary aldosteronism (PA) is an important, potentially curable cause of hypertension (HT), with hypokalemia in $9-37 \%$ of patients $[1,2]$. There has been controversy on its prevalence, studies report PA in possibly $>10 \%$ of HT patients and up to $22 \%$ in selected populations [3-5]. The main subtypes of PA are bilateral adrenal hyperplasia (BAH) and aldosterone-producing adrenal adenomas (APA) [6]. Compared to patients with essential HT, PA carries more risk of cardiovascular events and chronic kidney disease [7, 8]. Aldosterone itself may play an important role in vascular dysfunction [9]. Thus, diagnosing and treating PA correctly is of major importance and despite being complicated and expensive, screening patients with resistant HT for PA has been found to be cost-effective [10]. Adrenalectomy is recommended for 
unilateral disease (UD), resulting in cure or improvement in HT and hypokalemia [11-13]. Bilateral disease (BD) is treated with mineralocorticoid receptor antagonists (MRA) [14]. Treatment appears to reduce cardiovascular and renal complications and long-term mortality to levels seen in patients with essential HT [15-17]. Thus, diagnosing and treating PA appropriately decreases morbidity and mortality and increases quality of life $[18,19]$.

Even though outcomes after adrenalectomy have been reported $[20,21]$ and several studies have assessed treatment response for UD and BD, these studies do not necessarily rely on adrenal venous sampling (AVS) for subtyping or take into account the number of hypertension medications (HTM). Moreover, the follow-up period is either relatively short (3-4 years) or only a single visit [22-25]. Therefore, data regarding long term outcomes for AVS-confirmed BD is lacking.

In 2007, a standardized evidence-based work-up protocol for PA was introduced in Landspitali University Hospital of Iceland (LUH). Results from the first 5 years; 2007-2011, have been reported [26]. We present the results for the patients in the work-up for PA through the later 5 years of the study-period, 2012-2016. The objectives were to review characteristics and results of diagnostic procedures and histopathology for all patients diagnosed with PA and compare the two subgroups: UD and BD. Furthermore, the aim was to assess long-term outcome for all PA patients diagnosed in Iceland during the 10-year period 2007-2016 .

\section{Materials And Methods}

\section{Study_population}

Charts were viewed retrospectively for all patients in LUH, aged 18 and over, diagnosed with PA (ICD-10 Code E26) in 2012-2016. LUH is a referral center for the entire Icelandic population consisting of approximately 330 thousand inhabitants during the study period. The most common reason for referral was resistant hypertension and hypokalemia. A few patients had case detection and confirmation tests performed by endocrinologists in other Icelandic hospitals using protocols in line with the LUH protocol. If PA was confirmed or suspected, further work-up was directed in LUH, the only Icelandic hospital performing AVS and adrenalectomies. The same radiologist performed all AVS interventions, and the same surgeon performed all laparoscopic adrenalectomies during the study period.

\section{Case detection}

Patients were diagnosed using a standardized work-up protocol introduced in 2007 and described earlier by Jonsdottir et al [26]. The protocol was based on the Endocrine Society guidelines from 2008 [27] and in line with those published in 2016 [14].

Following referral, screening was performed after 4 weeks' discontinuation of HTM affecting the reninangiotensin-aldosterone system (RAAS), was considered positive if morning serum aldosterone (saldosterone) and/or $24 \mathrm{~h}$ urinary aldosterone excretion was increased, and direct renin concentration (DRC) decreased. Cut-off values were, as before, morning s-aldosterone concentration $>430 \mathrm{pmol} / \mathrm{l}$ 
and/or $24 \mathrm{~h}$ urinary aldosterone $>25 \mu \mathrm{g} / 24 \mathrm{~h}$ and DRC levels below the reference range from the manufacturer (see Analytical methods) [26].

\section{Confirmation and subtyping}

The saline infusion test (SIT) was used for confirmation. The patient remained recumbent after a $10 \mathrm{~h}$ bedrest and received an infusion of $2 \mathrm{I}$ of isotonic saline between 8 and 12 noon [27]. The test was considered positive if s-aldosterone was above $140 \mathrm{pmol} / \mathrm{l}$. Serum potassium was measured the day before SIT and pre- and post-infusion. Normal potassium levels were maintained during the test using appropriate potassium supplementation. Adrenal computed tomography (CT) scan was conducted. Synachten-stimulated AVS was performed for subtyping and lateralization index (LI) was calculated as previously described $[5,26]$. UD was defined as LI>3 along with contralateral suppression of aldosterone secretion [28]. Selectivity index was calculated and interpreted as described by Jacobsson et al [29].

\section{Treatment and follow-up}

Laparoscopic adrenalectomy was offered if UD was confirmed by AVS. Histopathological diagnosis was established using routine $\mathrm{H} \& \mathrm{E}$ staining. Patients diagnosed with $\mathrm{BD}$, or unable to undergo surgery, were offered treatment with selective (eplerenone) or non-selective (spironolactone) MRA. Follow-up was directed by the same endocrinologist at LUH or Laeknasetrid, a private outpatient clinic in Reykjavik, Iceland. Follow-up began one week after surgery or one month after initiation of MRA and was continued yearly. At each visit, blood samples for serum-potassium were examined, blood pressure measured, HTM reviewed and need for potassium supplementation assessed. End of follow-up period was January 1 st 2017 for patients diagnosed 2007-2011 and January 1st 2020 for patients diagnosed 2012-2016.

\section{Analytical methods}

Reference values for s-aldosterone in LUH changed in 2015 due to replacement of reagents. The manufacturing of the Coat-A-Count (Siemens, Los Angeles, CA, USA) substrate for radioimmunoassay (RIA) of aldosterone was discontinued and LUH switched to RIA substrates from DRG Instruments GmbH (Marburg, Germany). Manufacturers' reference values were used; s-aldosterone 111-860 pmol// (standing) and 28-444 pmol/l (recumbent) throughout 2014 and from $2015 \mathrm{~s}$-aldosterone $75-754 \mathrm{pmol} / \mathrm{l}$ (standing) and 36-402 pmol// (recumbent). Urinary aldosterone was measured using the same equipment and reagents. Urine was acidified $24 \mathrm{~h}$ before measuring aldosterone, reference range from manufacturer was used; 6-25 mcg/24 h (regular diet). DRC and serum-potassium were measured as described by Jonsdottir et al [26]. Manufacturers' reference values during the study period were for DRC 5-30 mIU/I (recumbent position) and 5-60 mIU/I (standing position) and for serum-potassium 3,5-4,8 mmol/l. Need for potassium supplementation was used as an assessment for hypokalemia since potassium levels were kept within normal limits whenever possible.

\section{Data analysis and ethical considerations}


We used descriptive statistics to describe outcomes from case detection, verification and subclassification of unilateral and bilateral PA. Wilcoxon rank-sum test was used for comparing nonnormally distributed continuous data, numbers presented as median and interquartile range (IQR). Analysis was performed using JMP, version 14.0.0, SAS Institute Inc. Tables regarding case detection and work-up display separately data from 2012-2016 and the combined 10-year period 2007-2016. A linear mixed effect model was applied for follow-up calculations for the 10-year period, using Stata Statistical softwear, release 13, StataCorp LP. The mean of available BP measurements prior to intervention (adrenalectomy or starting MRA) was compared to BP at 1, 2, .., 8 years of follow-up. A separate comparison was done for systolic blood pressure (SBP) and diastolic blood pressure (DBP). To compare HTM before and after treatment initiation, number of HTM at case detection was used as baseline. For comparison of BP and HTM at above-mentioned baseline vs median of follow-up, repeated-measures ttest was applied using JMP. For all statistical analysis, a two-sided P-value of $<0,05$ was considered statistically significant. Positive predictive value for CT with regards to lateralization was calculated by dividing number of patients with AVS-confirmed UD and ipsilateral adrenal nodule on CT by number of patients with unilateral adrenal nodule on CT.

Permissions were obtained from the National Bioethics Committee (License nr: VSNb2011110022/03.11) and the Icelandic Data Protection Authority, the Chief Medical Officer at LUH (License nr: OB/ei Tilv. 16, LSH 16) and from the Ethics Committee at Laeknasetrid Outpatient clinic (License nr: 1072016).

\section{Results}

\section{Overview}

Between 2012-2016, twenty-five patients completed full work-up and were diagnosed with PA; 14 with BD and 11 with UD, see Table 1 for baseline characteristics. Seven additional patients, listed in Online Resource 1, were diagnosed during the period and treated as BD, without undergoing AVS. Two of them were unable to discontinue treatment affecting the RAAS because of comorbidities, four had no SIT because of comorbidities (aldosterone/renin ratio, ARR, range 177-318 pmol/mlU) and one rejected AVS. These seven patients all had a long history of HT and hypokalemia and responded well to MRA. They have been excluded from statistical analysis regarding subgroups. One more patient completed work-up and was diagnosed with pheochromocytoma and therefore excluded. See Fig. 1 for overview of patients. Ten out of 11 patients with UD underwent adrenalectomy, all were histopathologically diagnosed with cortical adenoma. One patient emigrated before surgery. One patient with BD (no. 11, Online Resource 2) underwent adrenalectomy as an attempt to lower aldosterone levels since extensive HTM, including MRA, was insufficient and the patient was severely ill. The decision was made after expert consultation from abroad and repeated AVS. Histopathological examination revealed hyperplasia, as expected.

\section{Case detection}

From BG, 12/14 patients initially had morning s-aldosterone levels $>430 \mathrm{pmol} / \mathrm{l}$, all had values $>430$ $\mathrm{pmol} / \mathrm{I}$ on repetition. In UG, one patient had s-aldosterone $<430 \mathrm{pmol} / \mathrm{I}$ despite elevated $24 \mathrm{~h}$ urinary 
aldosterone, further addressed in Discussion chapter. Urinary aldosterone was $>25 \mathrm{mg} / 24 \mathrm{~h}$ in $5 / 10$ from BG, and 6/8 from UG. See Table 2 for results from case detection. Seven patients highly clinically suspective for PA had DRC $>5 \mathrm{mlU} / \mathrm{l}$ at case detection (range 5,6-21,0 $\mathrm{mlU} / \mathrm{l}$ ). They all went through full work-up and PA was confirmed, see Online Resource 3. Three of them had DRC $\leq 5 \mathrm{mlU} / \mathrm{l}$ later on and all seven had s-aldosterone $>190 \mathrm{pmol} / \mathrm{I}$ after SIT. For the 10 -year period, DRC at 8 am was significantly lower after $10 \mathrm{~h}$ bedrest (median 4,25; IQR 3,7) compared with that after 15 min sitting (median 5; IQR $9,4), p=0,03$.

\section{Saline infusion test}

All twenty-five confirmed PA patients had post-infusion s-aldosterone $>190 \mathrm{pmol} / \mathrm{l}$. No statistical difference was seen in post-infusion s-aldosterone for the two subgroups during the 5-year period, see Table 2. One patient rejected further work-up after SIT and six patients were unable to undergo SIT because of comorbidities. These seven patients are listed in Online Resource 1. Five patients underwent more than one SIT; one had subcutaneous saline infusion on the first test, one had borderline results and three needed repetition because of HTM interfering with RAAS and/or excessive liquorice consumption. These test results were excluded and the patient with excessive liquorice consumption was tested again after three months without liquorice consumption.

\section{$\underline{\text { CT results }}$}

Following a positive SIT, all patients underwent an adrenal CT scan. Roughly half of the patients with BD had an adrenal nodule on CT, see Table 2. In total, fifteen patients had a unilateral adrenal nodule, 9 of whom had ipsilateral UD confirmed by AVS, positive predictive value of 0,6. Six patients with adrenal nodule had BD.

\section{Adrenal venous sampling and success rate}

Thirty AVS were performed on 25 confirmed PA patients during the 5-year period. Four tests were excluded and repeated because of difficulties accessing the right adrenal vein and/or HTM greatly affecting RAAS. One patient from BG underwent a second AVS to plan adrenalectomy. See Online Resource 2 for borderline AVS results and repeated testing. All except one patient from UG had LI>4. Three patients from BG had LI>3; two of them did not have contralateral suppression of aldosterone secretion and one patient's sibling had previously been diagnosed with unilateral hyperplasia and relapsed a few years later, therefore the presented patient was classified and treated as BD. See Table 2 for $\mathrm{LI}$ of subgroups. Success rate for AVS based on selectivity index during the 5 -year period was $87 \%$ (26/30).

\section{Follow-up}

For the 10-year period, median duration of follow-up was 6 years, IQR 4. In the 2007-2016 cohort, patients went from $157 / 90-95 \mathrm{mmHg}$ under three HTM before specialized treatment, to $143-145 / 86-89 \mathrm{mmHg}$ under 1,8-2,3 HTM one year after initiation of specialized treatment. Both the UG and BG had a significant 
improvement in SBP during follow-up ( $p<0,001$ for both groups) and decreased need for HTM $(p=0,002$ and $p=0,04$, respectively). See Table 3 for results from follow-up of patients diagnosed with PA during 2007-2016. A decrease in DBP was seen in both groups, significant for the $U G(p<0,001)$. All 31 patients from BG were started on MRA treatment; $19(61 \%)$ on eplerenone and $12(39 \%)$ on spironolactone. The majority of the eplerenone group (14/19) were men. Two out of 27 (7\%) from UG and 1/31 (3\%) from BG needed potassium supplementation at the end of follow-up, significantly fewer than at case detection when all patients needed potassium supplementation ( $p<0,001$ for both subgroups).

Comparing values from median of follow-up (6 years) to pre-intervention, SBP and DBP decreased significantly in the UG (mean SBP $157 \pm 16$ to $138 \pm 15$ and DBP $95 \pm 11$ to $84 \pm 11$ ), $p=0,003$ and $p=0,01$, respectively. Same applies to the BG (SBP $158 \pm 19$ to $137 \pm 11$ and SBP $90 \pm 11$ to $84 \pm 7$ ), $p<0,001$ and $p<0,05$, respectively. From baseline to median of follow-up, number of HTM decreased for both groups (UG 2,8 $\pm 0,9$ to $2,6 \pm 1,5$ and $B G 2,4 \pm 1,0$ to $2 \pm 0,9$ ) although this difference was not statistically significant, $p=0,6$ and $p=0,1$, respectively. Based on PASO criteria [30] at 12 months post-op, 5/26 (19\%) from UG had complete clinical success and $21 / 26(81 \%)$ had partial clinical success.

\section{Discussion}

In this nationwide study, we describe the results from diagnostic work-up and treatment of PA patients diagnosed in Iceland 2012-2016, and the sum of 10 years, adding results from the 5 years published before [26]. During the presented 5-year period, 25 patients were diagnosed with SIT-and AVS-confirmed PA. Our unilateral and bilateral subgroups had fairly similar baseline characteristics which is in line with results from earlier studies $[15,24,25]$. Both groups benefitted from specialized treatment, indicated by sustained decline in BP and need for HTM during our long follow-up, and negligible need for potassium supplementation. Although treatment is initiated at a single time-point, we continue to see a reduction in BP and HTM count throughout the follow-up period. These important results emphasize keeping a close eye on PA patients after treatment initiation and the forthgoing successful effect of adrenalectomy in PA patients with UD. It would be interesting to view factors in-common of those who respond particularly well to treatment and predict who can be discharged early from follow-up.

According to studies, normokalemic hypertension is the most common presentation of PA, with hypokalemia in only $9-37 \%$ of patients [14]. Interestingly, all our patients needed potassium supplementation before initiation of specialized treatment. We believe most our patients' hypertension had been undertreated for a long time, possibly decreasing the effect of specialized treatment. This, along with insufficient doses of MRA, may explain the relatively small decrease in number of HTM in the BG.

We found DRC and s-aldosterone measurements to be very informative for case detection. In addition, it may be more convenient to interpret two separate values than one ratio (ARR) if patients are using HTM interfering with RAAS. One patient had morning s-aldosterone $<430 \mathrm{pmol} / \mathrm{I}-\mathrm{LI}$ was 7,7 and an adrenal adenoma was confirmed histopathologically. Interestingly, we found DRC to be significantly lower after 
$10 \mathrm{~h}$ bedrest than after $15 \mathrm{~min}$ of sitting. This underlines the complexity of interpreting renin and aldosterone values [31]. In our study, four patients (No. 13, 14, 16 and 17 in Online Resource 3 ) had renin values at the lower end of the reference range even though they were above our pre-set cut-off ( $5 \mathrm{mIU} / \mathrm{l})$. No other diagnoses were considered more likely. All four had a classical PA presentation - resistant HT with hypokalemia - and responded well to specialized treatment. Two of them even had histopathologically verified adrenal adenoma, the other two had BD. We found urinary aldosterone excretion to be greater among patients with UD. Higher excretion has been linked to better outcome after adrenalectomy [32]. Despite this, we decided to remove this measurement from our current protocol as it did not add enough information to other parts of work-up and is troublesome for outpatients.

We consider the SIT to be fairly convenient and reliable as a confirmatory test. Our 10-year results indicate that post-infusion aldosterone is higher in patients with UD. This highlights the importance of SIT as part of the PA work-up and is consistent with results from Weigel et al [33]. Approximately one-third of the 10-year BG had a nodule on adrenal-CT, underlining that CT can be misleading for subclassification $[34,35]$. This indicates the importance of AVS in subgroup analysis of PA. The majority of AVS interventions were successful (87\%) and gave a clear distinction between subgroups. One patient was diagnosed with UD yet treated as BD due to unusual family history described earlier.

A much higher number of PA cases would be expected in Iceland. Estimating that around $20 \%$ of adult Icelanders (between 200 and 250 thousand) have HT and $5-10 \%$ of HT is caused by PA, prevalence of PA should be a few thousand - making 58 (65) cases during a 10-year period an abnormally low number [1, 2]. We sense that many patients with resistant $H T$ in Iceland receive MRA without undergoing PA work-up. This could be due to work-up complexity and fear of changing a complicated combination of HTM. Making the work up easier for the patient as well as the doctor is important. As angiotensin converting enzyme inhibitors, angiotensin-receptor blockers and MRA are commonly used, we may need to emphasize that work-up on patients taking RAAS-interfering HTM (excluding MRA) is valid if renin is suppressed, although a washout of all interfering drugs is preferred [14]. As studies have indicated that aldosterone itself plays an important role in the increased cardiovascular risk among PA patients, it is vital to diagnose and treat according to evidence-based guidelines. Most studies, including ours, agree that specialized treatment is overall more successful for UD $[13,16,25]$. Also, to minimize risk of cardiometabolic events and death among unilateral PA patients on treatment, sufficient doses of MRA are essential [36].

\section{Strengths and limitations of the study.}

This nationwide study addressing uni- and bilateral PA, to our best knowledge, has both longer follow-up and more visits than previously published PA studies. Adding the earlier 5 years of the total 10 -year workup, makes the study quite extensive in this area and increases statistical impact. During the 10-year period, the same endocrinologist, interventional radiologist and surgeon supervised work-up and treatment of all patients making the process and registration even more standardized. However, our study is retrospective and not a screening-study; only those who underwent AVS were included in statistical 
analysis. Possibly, some patients with severe disease, not tolerating changes in HTM, were missed out. We excluded 7 PA patients not undergoing AVS. They all got MRA treatment although some of them may have had UD. We cannot reach a conclusion regarding biochemical outcome other than correction of hypokalemia as repeated measurements aldosterone and renin measurements were not performed nor SIT repeated [30]. Finally, clinical events were not explored and no standardized questionnaire was used for assessing well-being during follow-up.

The main external validity of our study is increased knowledge on the long-term efficacy of specialized PA treatment, especially on BD. Few studies have followed patients for this long and used the same work-up protocol throughout the whole study period.

\section{Conclusions}

In this nationwide study of PA in Iceland during 5-years, both unilateral and bilateral subgroups responded well to specialized treatment. The study indicates the importance of AVS in subgroup analysis of PA as adenoma on CT can be misleading. The relatively small number of patients diagnosed during the study period and good treatment response emphasizes the importance of screening patients with resistant hypertension for primary aldosteronism.

\section{Declarations}

\section{Acknowledgements}

The authors want to thank Ubaldo Benitez Hernandez, statistician and natural scientist at Landspitali University Hospital (LUH), for his help with statistical analysis regarding follow-up, and Gudmundur Sigthorsson, MD, PhD, at LUH for assessing laboratory values.

\section{Author contributions}

All authors contributed to the study conception and design. The manuscript was written by Hrafnhildur Gunnarsdóttir, MD, and all authors commented on previous versions. All authors have read and approved the final manuscript.

\section{Statements and Declarations}

The authors report no conflicts of interest to disclose.

\section{Funding}

This research was supported by a grant from the Landspitali University Hospital Research Fund (grant number B-2020-008).

\section{Competing interests}


The authors report no conflicts of interest to disclose.

\section{Ethics approval}

This retrospective study was approved by the National Bioethics Committee, Iceland (License nr: VSNb2011110022/03.11). The study was performed in line with the principles of the 1964 Declaration of Helsinki.

\section{References}

1. G.P. Rossi, G. Bernini, B. Fabris, C. Ferri, C. Ganzaroli, G. Giacchetti et al., Primary aldosteronism (PA) prevalence in Italy (papy) study: Results of a nationwide survey. Am. J. Hypertens. 18(5), 235a235aa (2005)

2. P. Mulatero, M. Stowasser, K.C. Loh, C.E. Fardella, R.D. Gordon, L. Mosso et al., Extensive personal experience - Increased diagnosis of primary aldosteronism, including surgically correctable forms, in centers from five continents. J Clin Endocr Metab 89(3), 1045-1050 (2004)

3. G.A. Kline, A.P.H. Prebtani, A.A. Leung, E.L. Schiffrin, Primary aldosteronism: a common cause of resistant hypertension. Can Med Assoc J 189(22), E773-E778 (2017)

4. G.P. Rossi, G. Bernini, C. Caliumi, G. Desideri, B. Fabris, C. Ferri et al., A prospective study of the prevalence of primary aldosteronism in 1,125 hypertensive patients. J Am Coll Cardiol 48(11), 22932300 (2006)

5. H.A. Sigurjonsdottir, M. Gronowitz, O. Andersson, R. Eggertsen, H. Herlitz, A. Sakinis et al., Unilateral adrenal hyperplasia is a usual cause of primary hyperaldosteronism. Results from a Swedish screening study. BMC Endocr Disord 12, 17 (2012)

6. R.D. Gordon, M. Stowasser, T.J. Tunny, S.A. Klemm, J.C. Rutherford, High incidence of primary aldosteronism in 199 patients referred with hypertension. Clin Exp Pharmacol Physiol 21(4), 315318 (1994)

7. E. Born-Frontsberg, M. Reincke, L.C. Rump, S. Hahner, S. Diederich, R. Lorenz et al., Cardiovascular and cerebrovascular comorbidities of hypokalemic and normokalemic primary aldosteronism: results of the German Conn's Registry. J Clin Endocrinol Metab 94(4), 1125-1130 (2009)

8. G.P. Rossi, G. Bernini, G. Desideri, B. Fabris, C. Ferri, G. Giacchetti et al., Renal damage in primary aldosteronism: results of the PAPY Study. Hypertension 48(2), 232-238 (2006)

9. C.S. Hung, S.H. Sung, C.W. Liao, C.T. Pan, C.C. Chang, Z.W. Chen et al., Aldosterone Induces Vascular Damage A Wave Reflection Analysis Study. Hypertension 74(3), 623-629 (2019)

10. G.L. Schwartz. Screening for adrenal-endocrine hypertension: overview of accuracy and costeffectiveness. Endocrinol Metab Clin North Am. 2011;40(2):279-94, vii

11. J.C. Rutherford, W.L. Taylor, M. Stowasser, R.D. Gordon, Success of surgery for primary aldosteronism judged by residual autonomous aldosterone production. World J Surg 22(12), 1243$1245(1998)$ 
12. N. Sukor, C. Kogovsek, R.D. Gordon, D. Robson, M. Stowasser, Improved quality of life, blood pressure, and biochemical status following laparoscopic adrenalectomy for unilateral primary aldosteronism. J Clin Endocrinol Metab 95(3), 1360-1364 (2010)

13. G.P. Rossi, M. Cesari, C. Cuspidi, G. Maiolino, M.V. Cicala, V. Bisogni et al., Long-term control of arterial hypertension and regression of left ventricular hypertrophy with treatment of primary aldosteronism. Hypertension 62(1), 62-69 (2013)

14. J.W. Funder, R.M. Carey, F. Mantero, M.H. Murad, M. Reincke, H. Shibata et al., The Management of Primary Aldosteronism: Case Detection, Diagnosis, and Treatment: An Endocrine Society Clinical Practice Guideline. J Clin Endocrinol Metab 101(5), 1889-1916 (2016)

15. G.P. Rossi, M. Cesari, C. Cuspidi, G. Maiolino, M.V. Cicala, V. Bisogni et al., Long-Term Control of Arterial Hypertension and Regression of Left Ventricular Hypertrophy With Treatment of Primary Aldosteronism. Hypertension 62(1), 62-69 (2013)

16. V.C. Wu, S.M. Wang, C.H. Chang, Y.H. Hu, L.Y. Lin, Y.H. Lin et al., Long term outcome of Aldosteronism after target treatments. Sci Rep-Uk. 2016;6

17. Y.Y. Chen, Y.H.H. Lin, W.C. Huang, E. Chueh, L. Chen, S.Y. Yang et al., Adrenalectomy Improves the Long-Term Risk of End-Stage Renal Disease and Mortality of Primary Aldosteronism. J Endocr Soc 3(6), 1110-1126 (2019)

18. M. Velema, T. Dekkers, A. Hermus, H. Timmers, J. Lenders, H. Groenewoud et al., Quality of Life in Primary Aldosteronism: A Comparative Effectiveness Study of Adrenalectomy and Medical Treatment. J Clin Endocrinol Metab 103(1), 16-24 (2018)

19. A.H. Ahmed, R.D. Gordon, N. Sukor, E. Pimenta, M. Stowasser, Quality of Life in Patients with Bilateral Primary Aldosteronism before and during Treatment with Spironolactone and/or Amiloride, Including a Comparison with Our Previously Published Results in Those with Unilateral Disease Treated Surgically. J Clin Endocr Metab 96(9), 2904-2911 (2011)

20. W.M.C.M. Vorselaars, S. Nell, E.L. Postma, R. Zarnegar, T. Drake, Q.Y. Duh et al., Clinical Outcomes After Unilateral Adrenalectomy for Primary Aldosteronism. Jama Surg. 2019;154(4)

21. O. Steichen, F. Zinzindohoue, P.F. Plouin, L. Amar, Outcomes of Adrenalectomy in Patients with Unilateral Primary Aldosteronism: A Review. Horm. Metab. Res. 44(3), 221-227 (2012)

22. A. Muth, O. Ragnarsson, G. Johannsson, B. Wangberg, Systematic review of surgery and outcomes in patients with primary aldosteronism. Brit J Surg 102(4), 307-317 (2015)

23. M.A. Grytaas, S.S. Stromsoy, J.T. Rorvik, J.B. Arnes, A. Heie, T. Arnesen et al., Clinical Characteristics and Long-Term Outcome of Primary Aldosteronism in a Norwegian Population. Horm. Metab. Res. 49(11), 838-846 (2017)

24. G. Bernini, A. Bacca, V. Carli, D. Carrara, G. Materazzi, P. Berti et al., Cardiovascular changes in patients with primary aldosteronism after surgical or medical treatment. J. Endocrinol. Invest. 35(3), 274-280 (2012)

25. K.S. Park, J.H. Kim, Y.S. Yang, A.R. Hong, D.H. Lee, M.K. Moon et al., Outcomes analysis of surgical and medical treatments for patients with primary aldosteronism. Endocr. J. 64(6), 623-632 (2017) 
26. G. Jonsdottir, J. Gudmundsson, G. Birgisson, H.A. Sigurjonsdottir, Primary aldosteronism: from case detection to histopathology with up to 6 years of follow-up. J Clin Hypertens (Greenwich). 2016

27. J.W. Funder, R.M. Carey, C. Fardella, C.E. Gomez-Sanchez, F. Mantero, M. Stowasser et al., Case detection, diagnosis, and treatment of patients with primary aldosteronism: an endocrine society clinical practice guideline. J Clin Endocrinol Metab 93(9), 3266-3281 (2008)

28. H. Umakoshi, K. Tanase-Nakao, N. Wada, T. Ichijo, M. Sone, N. Inagaki et al., Importance of contralateral aldosterone suppression during adrenal vein sampling in the subtype evaluation of primary aldosteronism. Clin Endocrinol 83(4), 462-467 (2015)

29. H. Jakobsson, K. Farmaki, A. Sakinis, O. Ehn, G. Johannsson, O. Ragnarsson, Adrenal venous sampling: the learning curve of a single interventionalist with 282 consecutive procedures. Diagn Interv Radiol 24(2), 89-93 (2018)

30. T.A. Williams, J.W.M. Lenders, P. Mulatero, J. Burrello, M. Rottenkolber, C. Adolf et al., Outcomes after adrenalectomy for unilateral primary aldosteronism: an international consensus on outcome measures and analysis of remission rates in an international cohort. Lancet Diabetes Endo 5(9), 689-699 (2017)

31. M. Stowasser, A.H. Ahmed, E. Pimenta, P.J. Taylor, R.D. Gordon, Factors Affecting the Aldosterone/Renin Ratio. Horm. Metab. Res. 44(3), 170-176 (2012)

32. A.M. Sawka, W.F. Young, G.B. Thompson, C.S. Grant, D.R. Farley, C. Leibson et al., Primary aldosteronism: Factors associated with normalization of blood pressure after surgery. Ann. Intern. Med. 135(4), 258-261 (2001)

33. M. Weigel, A. Riester, G. Hanslik, K. Lang, H.S. Willenberg, S. Endres et al., Post-saline infusion test aldosterone levels indicate severity and outcome in primary aldosteronism. Eur. J. Endocrinol. 172(4), 443-450 (2015)

34. A.T. Nanba, K. Nanba, J.B. Byrd, J.J. Shields, T.J. Giordano, B.S. Miller et al., Discordance between imaging and immunohistochemistry in unilateral primary aldosteronism. Clin Endocrinol 87(6), 665$672(2017)$

35. W.F. Young, A.W. Stanson, G.B. Thompson, C.S. Grant, D.R. Farley, J.A. van Heerden, Role for adrenal venous sampling in primary aldosteronism. Surgery 136(6), 1227-1235 (2004)

36. G.L. Hundemer, G.C. Curhan, N. Yozamp, M.L. Wang, A. Vaidya, Cardiometabolic outcomes and mortality in medically treated primary aldosteronism: a retrospective cohort study. Lancet Diabetes Endo 6(1), 51-59 (2018)

\section{Tables}

Table 1 Patients' demographics at diagnosis and comparison between subgroups. 


\begin{tabular}{|c|c|c|c|c|c|c|}
\hline Period & 2012-2016 & & & 2007-2016 & & \\
\hline PA subgroup & Unilateral & Bilateral & $\begin{array}{l}\mathrm{p}- \\
\text { value }\end{array}$ & Unilateral & Bilateral & $\begin{array}{l}\mathrm{p}- \\
\text { value }\end{array}$ \\
\hline Patients, n (\%) & $11(44 \%)$ & $14(56 \%)$ & - & 27 (47\%) & $\begin{array}{l}31 \\
(53 \%)\end{array}$ & - \\
\hline Male, n (\%) & $7(64 \%)$ & $7(50 \%)$ & - & $19(70 \%)$ & $\begin{array}{l}14 \\
(45 \%)\end{array}$ & $\bullet$ \\
\hline Age, years & $51(19)$ & $60(12)$ & 0,02 & $53(14)$ & $54(14)$ & 0,5 \\
\hline SBP, mmHg & $151(30)$ & $162(26)$ & 0,06 & $156(27)$ & $\begin{array}{l}158 \\
(29)\end{array}$ & 0,8 \\
\hline DBP, $\mathrm{mmHg}$ & $91(21)$ & $89(13)$ & 0,7 & $95(22)$ & $89(18)$ & 0,02 \\
\hline HTM, No. & $3(2)$ & $3(1,5)$ & 0,79 & $3(2)$ & $3(2)$ & 0,9 \\
\hline $\begin{array}{l}\text { K+ supplementation, } n \\
(\%)^{\mathrm{a}}\end{array}$ & $11(100 \%)$ & $\begin{array}{l}14 \\
(100 \%)\end{array}$ & • & 25 (93\%) & $\begin{array}{l}23 \\
(74 \%)\end{array}$ & - \\
\hline \multicolumn{7}{|l|}{ Histopathology } \\
\hline Adenoma, $\mathrm{n}(\%)^{\mathrm{b}}$ & $\begin{array}{l}10 / 10 \\
(100 \%)\end{array}$ & $\bullet$ & & $\begin{array}{l}21 / 26 \\
(81 \%)\end{array}$ & $\bullet$ & \\
\hline Hyperplasia, n (\%) & 0 & - & & $4 / 26(15 \%)$ & - & \\
\hline Inconclusive, n (\%) & 0 & - & & $1 / 26(4 \%)$ & - & \\
\hline
\end{tabular}

Abbreviations: PA, primary aldosteronism; No., number; SBP, systolic blood pressure; DBP, diastolic blood pressure; HTM, hypertension medication(s).

Data presented as median (interquartile range) or as number (percentage of cohort). Histopathology was assessed using routine H\&E staining.

Statistical comparison: Wilcoxon rank sum test.

${ }^{\mathrm{a} B e f o r e ~ i n i t i a t i o n ~ o f ~ s p e c i a l i z e d ~ t r e a t m e n t . ~}$

bone patient was lost to follow-up, hence denominators 10 and 26.

Table 2 Results from case detection, saline infusion test and subtyping. 


\begin{tabular}{|c|c|c|c|c|c|c|}
\hline Period & 2012-2016 & & & 2007-201€ & & \\
\hline PA subgroup & $\begin{array}{l}\text { Unilateral } \\
\mathrm{n}=11\end{array}$ & $\begin{array}{l}\text { Bilateral } \\
n=14\end{array}$ & p-value & $\begin{array}{l}\text { Unilateral } \\
n=27\end{array}$ & $\begin{array}{l}\text { Bilateral } \\
\mathrm{n}=31\end{array}$ & p-value \\
\hline S-aldosterone, pmol//a & $\begin{array}{l}745 \\
(600)\end{array}$ & $\begin{array}{l}778 \\
(439)\end{array}$ & 0,8 & $\begin{array}{l}746 \\
(752)\end{array}$ & $\begin{array}{l}794 \\
(1007)\end{array}$ & 0,8 \\
\hline U-aldosterone, $\mu \mathrm{g} / 24 \mathrm{~h}$ & $\begin{array}{l}30,9 \\
(20,8)\end{array}$ & $\begin{array}{l}15,4 \\
(5,9)\end{array}$ & $<0,001$ & $\begin{array}{l}33,9 \\
(22,6)\end{array}$ & $\begin{array}{l}24,6 \\
(18,5)\end{array}$ & $<0,001$ \\
\hline $\mathrm{DRC}, \mathrm{mlU} / \mathrm{I}^{\mathrm{b}}$ & $4,2(2,2)$ & $3,7(3,5)$ & 0,7 & $4,9(5,2)$ & $\begin{array}{l}5,4 \\
(17,6)\end{array}$ & 0,09 \\
\hline DRC after $10 \mathrm{~h}$ bed rest, $\mathrm{mlU} / \mathrm{I}$ & $5,5(4,5)$ & $3,4(2,0)$ & 0,07 & $4,9(3,5)$ & $3,8(4,6)$ & 0,6 \\
\hline ARR, pmol/mlUc & $\begin{array}{l}206 \\
(171)\end{array}$ & $\begin{array}{l}169 \\
(217)\end{array}$ & 0,5 & $\begin{array}{l}165 \\
(148)\end{array}$ & $\begin{array}{l}99 \\
(173)\end{array}$ & 0,07 \\
\hline $\begin{array}{l}\text { Post-infusion s-aldosterone, } \\
\mathrm{pmol} / /^{\mathrm{d}}\end{array}$ & $\begin{array}{l}381 \\
(458)\end{array}$ & $\begin{array}{l}292 \\
(297)\end{array}$ & 0,3 & $\begin{array}{l}385 \\
(289)\end{array}$ & $\begin{array}{l}251 \\
(296)\end{array}$ & 0,01 \\
\hline CT nodule, $\mathrm{n}(\%)$ & $9(82 \%)$ & $6(43 \%)$ & $\bullet$ & $19(70 \%)$ & $\begin{array}{l}10 \\
(32 \%)\end{array}$ & - \\
\hline LI after AVS & $7,7(13,1)$ & $2,1(1,7)$ & $<0,0001$ & $7,5(8,9)$ & $1,7(1,0)$ & $<0,0001$ \\
\hline
\end{tabular}

Abbreviations: PA, primary aldosteronism; s-aldosterone; serum aldosterone, U-aldosterone, urinary aldosterone; DRC, direct renin concentration; SIT, saline infusion test; ARR, aldosterone/renin ratio; saldosterone, serum aldosterone; CT, computed tomography; LI, lateralization index; AVS, adrenal venous sampling.

Data presented as median (interquartile range) or as ratio (percentage of cohort). Statistical comparison: Wilcoxon rank sum test.

a measured at 8 am after 15 min. of sitting.

${ }^{b}$ measured at $8 \mathrm{am}$ after $15 \mathrm{~min}$. of sitting.

${ }^{c}$ a common and recommended cut-off according to current ECE guidelines is $91 \mathrm{pmol} / \mathrm{mIU}$ [14].

${ }^{d}$ measured after $4 \mathrm{~h}$ iv saline infusion.

Table 3 Comparison of blood pressure and number of hypertension medications in patients diagnosed with primary aldosteronism 2007-2016, before and after adrenalectomy (unilateral disease) or initiation of mineralocorticoid receptor antagonists (bilateral disease). 


\begin{tabular}{|c|c|c|c|c|c|c|c|}
\hline \multirow[t]{2}{*}{$\begin{array}{l}\text { Unilateral } \\
n=27\end{array}$} & & & & \multicolumn{4}{|l|}{ Bilateral } \\
\hline & $\begin{array}{l}\text { SBP } \\
(\mathrm{mmHg})\end{array}$ & $\begin{array}{l}\text { DBP } \\
(\mathrm{mmHg})\end{array}$ & $\begin{array}{l}\text { HTM, } \\
\text { No. }\end{array}$ & & $\begin{array}{l}\text { SBP } \\
(\mathrm{mmHg})\end{array}$ & $\begin{array}{l}\text { DBP } \\
(\mathrm{mmHg})\end{array}$ & $\begin{array}{l}\text { HTM, } \\
\text { No. }\end{array}$ \\
\hline \multirow{2}{*}{$\begin{array}{l}\text { Prior to } \\
\text { surgery } \\
n=27\end{array}$} & $157 \pm 16$ & $95 \pm 11$ & $3,0 \pm 1,3$ & $\begin{array}{l}\text { Prior to } \\
\text { MRA }\end{array}$ & $157 \pm 19$ & $90 \pm 11$ & $3,0 \pm 1,4$ \\
\hline & & & & $n=31$ & & & \\
\hline \multirow{2}{*}{$\begin{array}{l}\text { 1y post-op } \\
n=25\end{array}$} & $143 \pm 20$ & $89 \pm 11$ & $1,8 \pm 1,7$ & $\begin{array}{l}\text { 1y after } \\
\text { MRA }\end{array}$ & $145 \pm 18$ & $86 \pm 14$ & $2,3 \pm 1,1$ \\
\hline & & & & $n=27$ & & & \\
\hline \multirow{2}{*}{$\begin{array}{l}2 y \text { post-op } \\
n=22\end{array}$} & $138 \pm 23$ & $84 \pm 13$ & $1,8 \pm 1,5$ & $\begin{array}{l}2 y \text { after } \\
\text { MRA }\end{array}$ & $143 \pm 20$ & $89 \pm 13$ & $2,4 \pm 1,2$ \\
\hline & & & & $n=29$ & & & \\
\hline \multirow{2}{*}{$\begin{array}{l}\text { 3y post-op } \\
n=13\end{array}$} & $141 \pm 20$ & $89 \pm 13$ & $2,1 \pm 1,7$ & $\begin{array}{l}\text { 3y after } \\
\text { MRA }\end{array}$ & $146 \pm 22$ & $89 \pm 14$ & $2,3 \pm 1,1$ \\
\hline & & & & $n=25$ & & & \\
\hline \multirow{2}{*}{$\begin{array}{l}\text { 4y post-op } \\
n=14\end{array}$} & $137 \pm 18$ & $84 \pm 11$ & $2,4 \pm 1,6$ & $\begin{array}{l}\text { 4y after } \\
\text { MRA }\end{array}$ & $138 \pm 19$ & $84 \pm 12$ & $2,4 \pm 1,2$ \\
\hline & & & & $n=23$ & & & \\
\hline \multirow{2}{*}{$\begin{array}{l}\text { 5y post-op } \\
n=12\end{array}$} & $138 \pm 17$ & $86 \pm 10$ & $2,5 \pm 1,9$ & $\begin{array}{l}\text { 5y after } \\
\text { MRA }\end{array}$ & $144 \pm 15$ & $87 \pm 8$ & $2,2 \pm 1,1$ \\
\hline & & & & $\mathrm{n}=21$ & & & \\
\hline \multirow{2}{*}{$\begin{array}{l}\text { 6y post-op } \\
n=10\end{array}$} & $138 \pm 15$ & $84 \pm 11$ & $2,6 \pm 1,5$ & $\begin{array}{l}\text { 6y after } \\
\text { MRA }\end{array}$ & $137 \pm 11$ & $84 \pm 7$ & $2,0 \pm 0,9$ \\
\hline & & & & $n=18$ & & & \\
\hline \multirow{2}{*}{$\begin{array}{l}\text { 7y post-op } \\
n=6\end{array}$} & $138 \pm 16$ & $73 \pm 21$ & $1,8 \pm 1,2$ & $\begin{array}{l}\text { 7y after } \\
\text { MRA }\end{array}$ & $139 \pm 13$ & $86 \pm 13$ & $1,9 \pm 0,9$ \\
\hline & & & & $n=9$ & & & \\
\hline \multirow{2}{*}{$\begin{array}{l}\text { 8y post-op } \\
n=3\end{array}$} & $130 \pm 7$ & $79 \pm 2$ & $1,5 \pm 0,7$ & $\begin{array}{l}\text { 8y after } \\
\text { MRA }\end{array}$ & $142 \pm 15$ & $70 \pm 7$ & $2,7 \pm 0,6$ \\
\hline & & & & $n=3$ & & & \\
\hline Coefficient $^{a}$ & -3 & -2 & $-0,14$ & Coefficient $^{a}$ & -2 & $-0,5$ & $-0,05$ \\
\hline $95 \% \mathrm{Cl}$ & $-4,2 ;-1,7$ & $-2,9 ;-1,2$ & $\begin{array}{l}-0,2 ; \\
-0,05\end{array}$ & $95 \% \mathrm{Cl}$ & $-2,9 ;-1,0$ & $-1,1 ;+0,1$ & $\begin{array}{l}-0,1 ; \\
-0,001\end{array}$ \\
\hline p-value & $<0,001$ & $<0,001$ & 0,002 & p-value & $<0,001$ & 0,1 & 0,04 \\
\hline
\end{tabular}


Abbreviations: SBP, systolic blood pressure; SD, standard deviation; DBP, diastolic blood pressure; HTM, hypertension medication(s); MRA, mineralocorticoid receptor antagonist; y, year(s); $\mathrm{Cl}$, confidence interval.

Blood pressure values presented as mean \pm SD.

${ }^{a}$ Coefficient indicates the slope of the mixed effect model; mmHg or HTM per year.

\section{Figures}

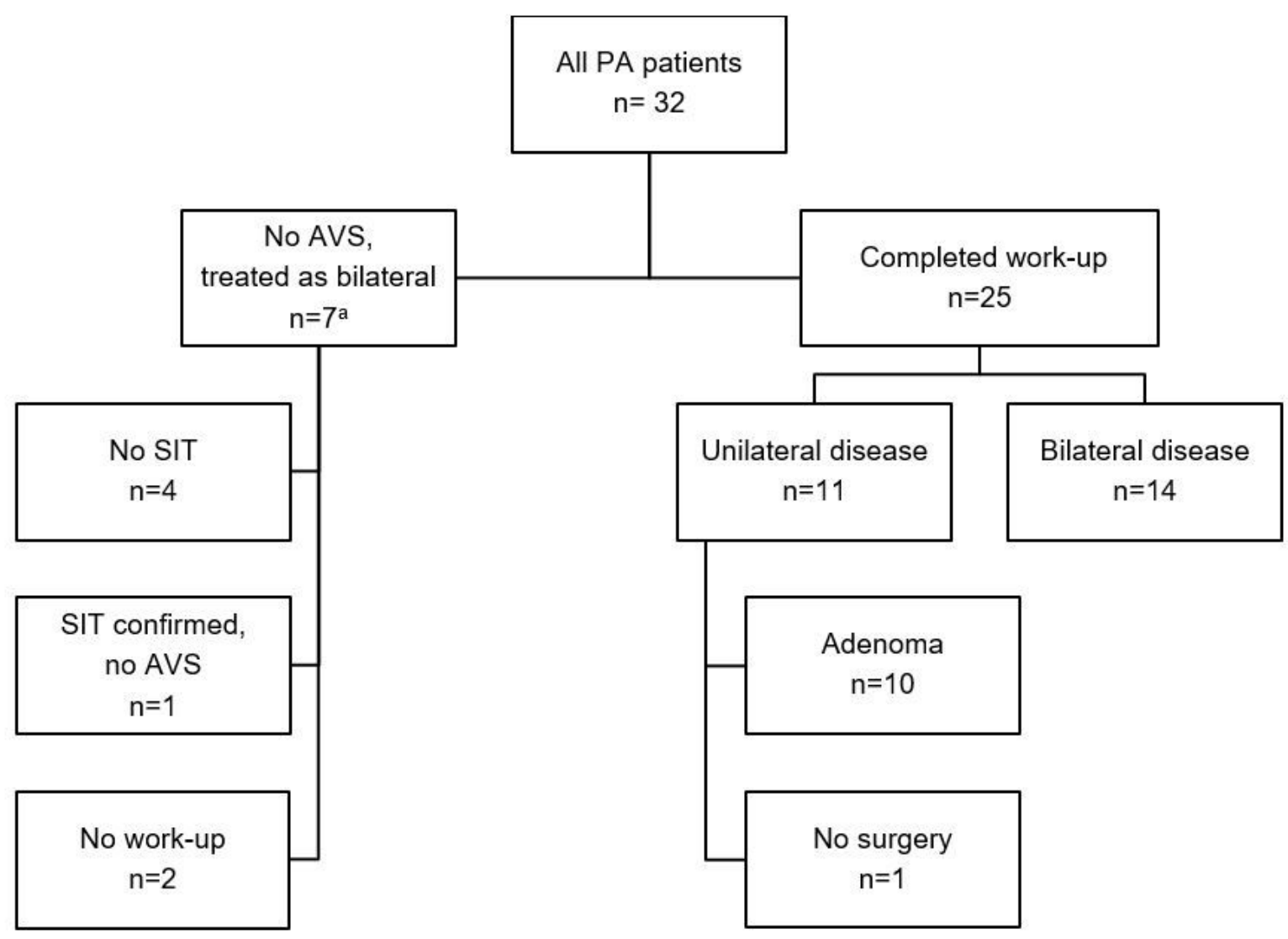

\section{Figure 1}

Overview of patients diagnosed with PA in Iceland 2012-2016 Abbreviations: PA, primary aldosteronism; AVS, adrenal venous sampling; SIT, saline infusion test. aExcluded from statistical analysis.

\section{Supplementary Files}

This is a list of supplementary files associated with this preprint. Click to download.

- ESM1.pdf 
- ESM2.pdf

- ESM3.pdf

Page 17/17 